\title{
Article \\ Performance of High-Layer-Thickness Ti6Al4V Fabricated by Electron Beam Powder Bed Fusion under Different Accelerating Voltage Values
}

\author{
Hongxin Li ${ }^{1,2,3}$, Xiaoyu Liang ${ }^{1,2,3}$, Yang $\mathrm{Li}^{1,2,3}$ and Feng Lin ${ }^{1,2,3, *}$ \\ 1 Department of Mechanical Engineering, Tsinghua University, Beijing 100084, China; lhx12kf@163.com (H.L.); \\ xiaoyu_liang@tsinghua.edu.cn (X.L.); liyangthu8@163.com (Y.L.) \\ 2 Key Laboratory for Advanced Materials Processing Technology, Ministry of Education of China, \\ Beijing 100084, China \\ 3 Bio-Manufacturing and Rapid Forming Technology Key Laboratory of Beijing, Tsinghua University, \\ Beijing 100084, China \\ * Correspondence: linfeng@mail.tsinghua.edu.cn; Tel.: +86-10-6278-8675
}

check for

updates

Citation: Li, H.; Liang, X.; Li, Y.;

Lin, F. Performance of

High-Layer-Thickness Ti6Al4V

Fabricated by Electron Beam Powder

Bed Fusion under Different

Accelerating Voltage Values.

Materials 2022, 15, 1878.

https://doi.org/10.3390/

ma15051878

Academic Editor: Amir Mostafaei

Received: 25 January 2022

Accepted: 25 February 2022

Published: 3 March 2022

Publisher's Note: MDPI stays neutral with regard to jurisdictional claims in published maps and institutional affiliations.

Copyright: () 2022 by the authors Licensee MDPI, Basel, Switzerland. This article is an open access article distributed under the terms and conditions of the Creative Commons Attribution (CC BY) license (https:// creativecommons.org/licenses/by/ $4.0 /)$.

\begin{abstract}
The electron beam powder bed fusion (EB-PBF) process is typically carried out using a layer thickness between 50 and $100 \mu \mathrm{m}$ with the accelerating voltage of $60 \mathrm{kV}$ for the electron beam. This configuration ensures forming accuracy but limits building efficiency. The augmentation of the accelerating voltage enlarges the molten pool due to the rise in penetrability, suggesting that a higher layer thickness can be used. Therefore, the effects of layer thickness and accelerating voltage were investigated simultaneously in this study to explore the feasibility of efficiency improvement. Ti6Al4V was fabricated by EB-PBF using layer thicknesses of 200 and $300 \mu \mathrm{m}$. Two accelerating voltage values of 60 and $90 \mathrm{kV}$ were used to study their effects under expanded layer thickness. The results reveal that dense parts with the ultimate tensile strength higher than $950 \mathrm{MPa}$ and elongation higher than $9.5 \%$ could be fabricated even if the layer thickness reached $300 \mu \mathrm{m}$, resulting in a building rate of up to $30 \mathrm{~mm}^{3} / \mathrm{s}$. The expansion of the layer thickness could decrease the minimum bulk energy density needed to fabricate dense parts and increase the $\alpha$ platelet thickness, which improved the energy efficiency. However, expanding layer thickness had a significant negative effect on surface roughness, but it could be improved by applying augmented accelerating voltage.
\end{abstract}

Keywords: electron beam powder bed fusion; accelerating voltage; Ti6Al4V; high layer thickness; properties

\section{Introduction}

Electron beam powder bed fusion (EB-PBF) is a kind of additive manufacturing technology which uses electron beams to selectively melt the powder layer by layer based on three-dimensional (3D) digital models and form 3D parts [1,2]. Compared with subtractive manufacturing technologies, parts with low thermal stress and arbitrary complex structures can be fabricated by EB-PBF due to the high powder-bed temperature and support effect provided by the sintered powder bed during the manufacturing process. The recycling of the sintered powder greatly increases the material utilization rate. In recent years, metal parts with high mechanical properties have been successfully fabricated by EB-PBF using different materials [3-9], which demonstrates promising prospects in aerospace, medicine and other fields.

As a powder bed fusion process, layer thickness plays a key role in EB-PBF. Generally, the typical layer thickness for the EB-PBF process varies between 50 and $100 \mu \mathrm{m}[10,11]$. This is larger than the typical layer thickness between 20 and $50 \mu \mathrm{m}$ used in laser powder bed fusion (L-PBF) which uses a laser as the heat source to melt the metal powder. A smaller layer thickness results in higher dimensional accuracy and surface roughness, but a lower 
building rate, which increases the building cost and limits its ability to form large-scale parts [12].

Serval research studies have demonstrated that a layer thickness between 100 and $250 \mu \mathrm{m}$ could be used for the L-PBF process to fabricate dense parts with qualified mechanical properties [13-18]. A building rate up to $12 \mathrm{~mm}^{3} / \mathrm{s}$ could be reached, which is about 10 times larger than the typical L-PBF process [16]. These research studies showed that, when a higher layer thickness was applied, higher line energy was needed, which amplified the keyhole and splashing effects and resulted in pore defects. However, these phenomena could be suppressed by adopting a higher beam diameter, by which a more stable molten pool could be obtained [19]. These findings indicate that expanding layer thickness is an effective way to improve the building rate.

However, to date, most of those studies are carried out by L-PBF and few studies about the effects of high layer thickness on EB-PBF are reported because of the equipment limitations. The ability to fabricate parts using high layer thickness by EB-PBF still lacks validation and the effect of high layer thickness on EB-PBF-manufactured parts is still unclear. Tang et al. [20] fabricated the Ti- $45 \mathrm{Al}-7 \mathrm{Nb}-0.3 \mathrm{~W}$ alloy with a layer thickness of 200-300 $\mu \mathrm{m}$ using a self-made EB-PBF machine and obtained a relative density up to $98.3 \%$. Rännar et al. [21] manufactured $316 \mathrm{~L}$ stainless steel with a layer thickness of 100-200 $\mu \mathrm{m}$ using the A2 ARCAM machine, where the density of the sample with $200 \mu \mathrm{m}$ layer thickness was $3.2 \%$ lower than that of the sample with $100 \mu \mathrm{m}$ layer thickness. These results indicate that lack of fusion is the primary defect for EB-PBF parts manufactured with high layer thickness.

For the EB-PBF process, the power $(P)$ of the electron beam is determined by the product of the electron beam current $(I)$ and accelerating voltage $(U)$. The accelerating voltage determines the speed of the electrons and is fixed at $60 \mathrm{kV}$ in most EB-PBF equipment. However, previous research studies showed that the molten pool depth increased significantly when the accelerating voltage was augmented, which was caused by the higher penetrability of a higher speed electron beam [22,23]. Hence, when considering reducing unfused defects, higher accelerating voltage helps fabricate parts using high layer thickness.

In this study, the possibility of using high layer thickness (up to $300 \mu \mathrm{m}$ ) in EB-PBF process and the possibility where the accelerating voltage could be used to improve the forming ability of high layer thickness were investigated. An EB-PBF machine with an accelerating voltage varying between 60 and $90 \mathrm{kV}$ was developed. Ti6Al4V parts were built using both accelerating voltage values using layer thicknesses of 200 and $300 \mu \mathrm{m}$, respectively. The effects of the parameters on the density, surface roughness, microstructure and tensile properties of the as-built samples were studied.

\section{Experimental Procedure}

\subsection{Materials}

Gas-atomized Ti6Al4V Grade 23 alloy powder (Beijing AVIC Matt Co., Ltd., Beijing, China) with a size range of $45-105 \mu \mathrm{m}$ was used for this study. The flowability was $25.9 \mathrm{~s} / 50 \mathrm{~g}$, which was measured using a hall flowmeter (BT-200; Bettersize Instruments Ltd., Dandong, China). The powder morphology is shown in Figure 1a; the powder size distribution was measured using a laser particle size analyzer (Mastersizer 3000, Malvern Panalytical Ltd., Worcester, UK) and is shown in Figure 1b; and the chemical composition is listed in Table 1.

\subsection{Equipment and Manufacturing Process}

The tests were carried out using EB-PBF-250 equipment developed by Tsinghua University [24,25]. The accelerating voltage of this equipment was variable between 60 and $90 \mathrm{kV}$. A Ti6Al4V alloy sheet with a thickness of $10 \mathrm{~mm}$ was used as the substrate. The substrate was preheated to $700{ }^{\circ} \mathrm{C}$ before the powder spreading process and the powder bed was preheated to $700^{\circ} \mathrm{C}$ before the melting process. Building samples with a cross-section 
of $20 \times 20 \mathrm{~mm}^{2}$ and a height of $8 \mathrm{~mm}$ were fabricated under a constant pressure of $0.1 \mathrm{~Pa}$ with argon backfilling.
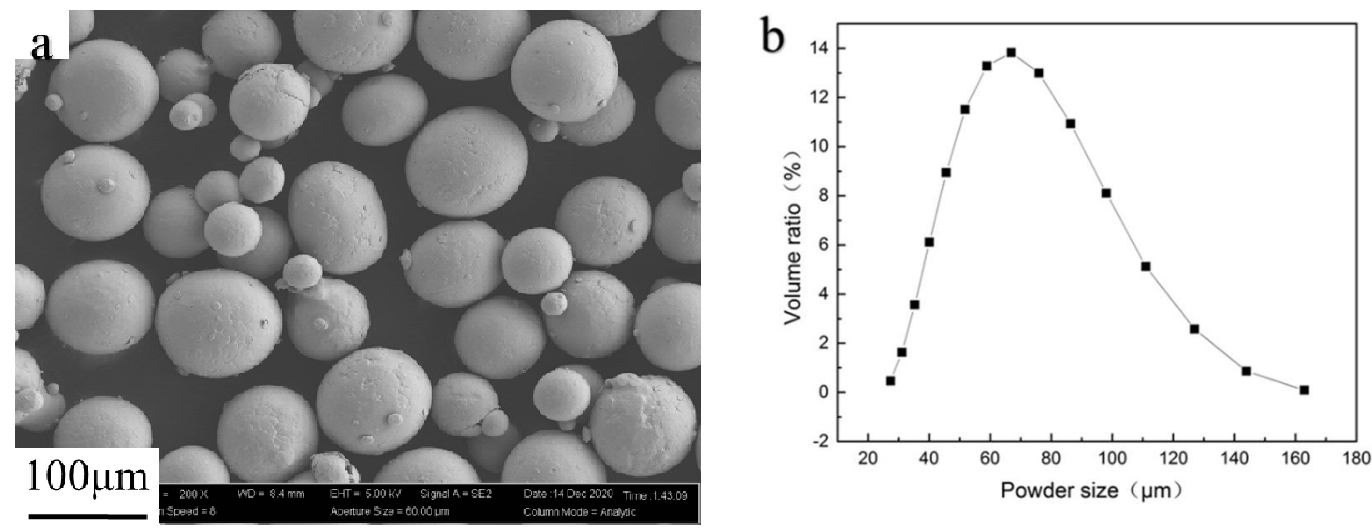

Figure 1. (a) Morphology of Ti6Al4V powder (reprinted with permission from Ref. [22], Copyright 2022 Elsevier); (b) powder size distribution of Ti6Al4V powder.

Table 1. Composition of Ti6Al4V powder.

\begin{tabular}{ccccccc}
\hline Element & Ti & Al & V & Fe & O & N \\
\hline wt. $\%$ & Balance & 6.16 & 4.30 & 0.16 & 0.09 & $<0.01$ \\
\hline
\end{tabular}

An "S-mode" strategy was adopted for the melting process, as depicted in Figure 2a. The scanning direction between adjacent layers was rotated by $90^{\circ}$ and the scanning direction between adjacent scanning lines was rotated by $180^{\circ}$. The bulk energy density $E\left(\mathrm{~J} / \mathrm{mm}^{3}\right)$, referred to the energy obtained in unit volume by material during the electron beam melting, was used to characterize the heat input. It is calculated by

$$
E=\frac{U I}{h v L}
$$

where $U$ denotes the accelerating voltage $(\mathrm{kV}), I$ is the electron beam current $(\mathrm{mA}), h$ denotes the hatching space between adjacent scanning lines $(\mathrm{mm}), v$ denotes the scan speed $(\mathrm{mm} / \mathrm{s})$ and $L$ is the layer thickness $(\mu \mathrm{m})$. In this experiment, the scanning speed was fixed at $500 \mathrm{~mm} / \mathrm{s}$ and the hatching space was $0.2 \mathrm{~mm}$.

Two layer thicknesses, 200 and $300 \mu \mathrm{m}$, were used to investigate the effect of high layer thickness on the forming quality of the as-built samples. Besides the accelerating voltage of $60 \mathrm{kV}, 90 \mathrm{kV}$ was also used to evaluate the feasibility of forming specimens with high layer thickness using high accelerating voltage. In all experiments, the electron beam was focused to the smallest spot diameter that the equipment could achieve (approximately $400 \mu \mathrm{m}$ at $60 \mathrm{kV}$ and approximately $300 \mu \mathrm{m}$ at $90 \mathrm{kV}$ ) during the melting process, which could suppress the keyhole and splashing effects because of the larger spot diameter than the spot diameter below $100 \mu \mathrm{m}$ in L-PBF [19]. The processing parameters for all samples are listed in Table 2; three different bulk energy densities were used and the beam current was determined according to Equation (1).

\subsection{Characterization}

The sample densities were measured using the Archimedes principle with equipment ADVENTURER, AR423DCN. The nominal density of Ti6Al4V was calculated as $4.42 \mathrm{~g} / \mathrm{cm}^{3}$ [26]. The surface roughness measurements were carried out using a 3D confocal microscope (Phase Shift MicroXAM-3D). The arithmetic average value (Ra) was used for the surface roughness analyses. During the surface roughness measurements, the measured direction for the lateral surface was parallel to the build direction and the measured direction for the upper surface was perpendicular to the scanning direction. 

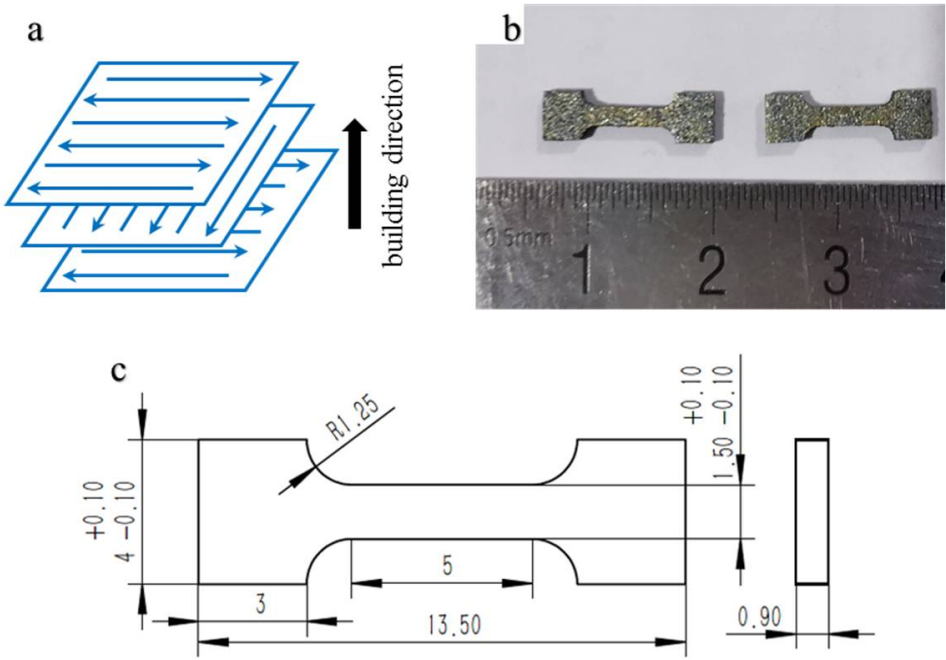

$\bullet$ building direction

Figure 2. (a) Scanning strategy; (b) tensile samples; (c) dimensions (in mm) of tensile samples (reprinted with permission from Ref. [22], Copyright 2022 Elsevier).

Table 2. Process parameters of as-built samples.

\begin{tabular}{|c|c|c|c|c|}
\hline Sample Number & Layer Thickness $(\mu \mathrm{m})$ & Accelerating Voltage $(\mathrm{kV})$ & Beam Current (mA) & Energy Density $\left(\mathrm{J} / \mathrm{mm}^{3}\right)$ \\
\hline 1 & 200 & 60 & 5 & 15 \\
\hline 2 & 200 & 60 & 6.67 & 20 \\
\hline 3 & 200 & 60 & 8.33 & 25 \\
\hline 4 & 300 & 60 & 7.5 & 15 \\
\hline 5 & 300 & 60 & 10 & 20 \\
\hline 6 & 300 & 60 & 12.5 & 25 \\
\hline 7 & 200 & 90 & 3.33 & 15 \\
\hline 8 & 200 & 90 & 4.44 & 20 \\
\hline 9 & 200 & 90 & 5.56 & 25 \\
\hline 10 & 300 & 90 & 5 & 15 \\
\hline 11 & 300 & 90 & 6.67 & 20 \\
\hline 12 & 300 & 90 & 8.33 & 25 \\
\hline
\end{tabular}

The surface morphologies and microstructures were observed using a Sigma 300 field emission scan electron microscope (FESEM), which operated at $5 \mathrm{kV}$. The samples were polished and then etched for $20 \mathrm{~s}$ with Kroll's reagent (vol. $1 \% \mathrm{HNO}_{3}$, vol. $2 \% \mathrm{HF}$, vol. $97 \%$ $\mathrm{H}_{2} \mathrm{O}$ ) to better reveal the microstructure. Tensile samples, shown in Figure $2 b$, were tested using a Zwick Z2.5 TH tensile test machine at $25^{\circ} \mathrm{C}$. The strain rate was $0.5 \times 10^{-3} / \mathrm{s}$ and the test direction was perpendicular to the building direction. The dimensions of the tensile samples are depicted in Figure 2c.

\section{Results and Discussion}

\subsection{Relative Densities and Surface Morphologies}

The density results for the as-built samples are listed in Table 3 and plotted in Figure 3. The dense parts were defined with a density greater than $99.5 \%$. It can be observed that dense parts could be achieved at the bulk energy density of $25 \mathrm{~J} / \mathrm{mm}^{3}$ for both layer thicknesses and accelerating voltages. Furthermore, when the layer thickness expanded from $200 \mu \mathrm{m}$ to $300 \mu \mathrm{m}$, the minimum bulk energy density needed to fabricate dense parts reduced from $25 \mathrm{~J} / \mathrm{mm}^{3}$ to $20 \mathrm{~J} / \mathrm{mm}^{3}$ at the accelerating voltage of $60 \mathrm{kV}$ and from $20 \mathrm{~J} / \mathrm{mm}^{3}$ to $15 \mathrm{~J} / \mathrm{mm}^{3}$ at the accelerating voltage of $90 \mathrm{kV}$. 
Table 3. Relative densities for all samples.

\begin{tabular}{ccccccc}
\hline Sample Number & $\mathbf{1}$ & $\mathbf{2}$ & $\mathbf{3}$ & $\mathbf{4}$ & $\mathbf{5}$ & $\mathbf{6}$ \\
\hline Relative density $(\%)$ & $93.94 \pm 0.15$ & $95.90 \pm 0.13$ & $99.60 \pm 0.10$ & $97.17 \pm 0.17$ & $99.86 \pm 0.04$ & $99.66 \pm 0.07$ \\
\hline Sample Number & $\mathbf{7}$ & $\mathbf{8}$ & $\mathbf{9}$ & $\mathbf{1 0}$ & $\mathbf{1 1}$ & $\mathbf{1 2}$ \\
\hline Relative density $(\%)$ & $95.91 \pm 0.10$ & $99.77 \pm 0.12$ & $99.71 \pm 0.05$ & $99.73 \pm 0.13$ & $99.87 \pm 0.08$ & $99.88 \pm 0.07$ \\
\hline
\end{tabular}

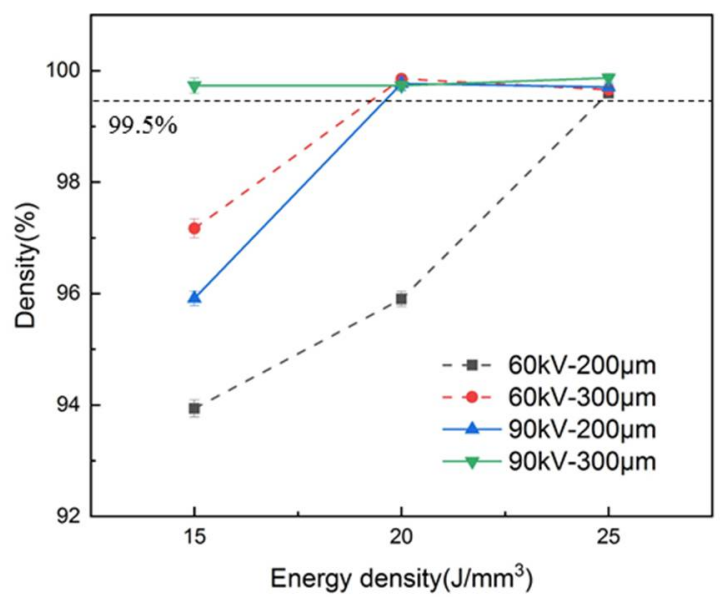

Figure 3. Relative densities of as-built samples.

The upper and lateral surface morphologies of the dense samples fabricated with the bulk energy density of $25 \mathrm{~J} / \mathrm{mm}^{3}$ under different layer thicknesses and different accelerating voltages were evaluated using FESEM (as shown in Figures 4 and 5) and 3D confocal microscope (as shown in Figures 6 and 7), respectively. The surface roughness values of those samples are plotted in Figure 8.

As shown in Figures 4 and 6, the single-line scanning tracks could be observed, which caused the surface fluctuations and resulted in roughness (Ra) values between 5 and $10 \mu \mathrm{m}$ of the upper surface. No significant differences could be observed for the four upper surfaces fabricated using different parameters. However, the surface roughness of the upper surface at higher layer thickness was slightly increased and decreased by augmenting the accelerating voltage from 60 to 90 kV, as shown in Figure 8a. Compared to the upper surface, the lateral surface was more uneven and had a greater surface roughness. The semi-elliptical cross-section of the molten pool, combining the step effect caused by the layer thickness, resulted in a structure with alternating peaks and valleys perpendicular to the building direction, as shown in Figures 5 and 7 . Furthermore, the fluctuation of the molten pool and the incompletely melted powder adhered to the lateral surface could also exaggerate the lateral surface roughness. These effects resulted in lateral surface roughness values between 39 and $60 \mu \mathrm{m}$. Moreover, the surface roughness of the lateral surface at higher layer thickness was also increased and decreased by augmenting the accelerating voltage from 60 to $90 \mathrm{kV}$, as shown in Figure 8b, which shows the same trend as the upper surface.

With the expansion of layer thickness, the stochastic effect of the powder bed and the step effect caused by the melting tracks intensify, which exaggerates the surface roughness. The augmentation of accelerating voltage enlarges the melting depth, which improves the stability of the melt pool and reduces the track fluctuation [27]. Therefore, augmenting the accelerating voltage improves the surface roughness. 

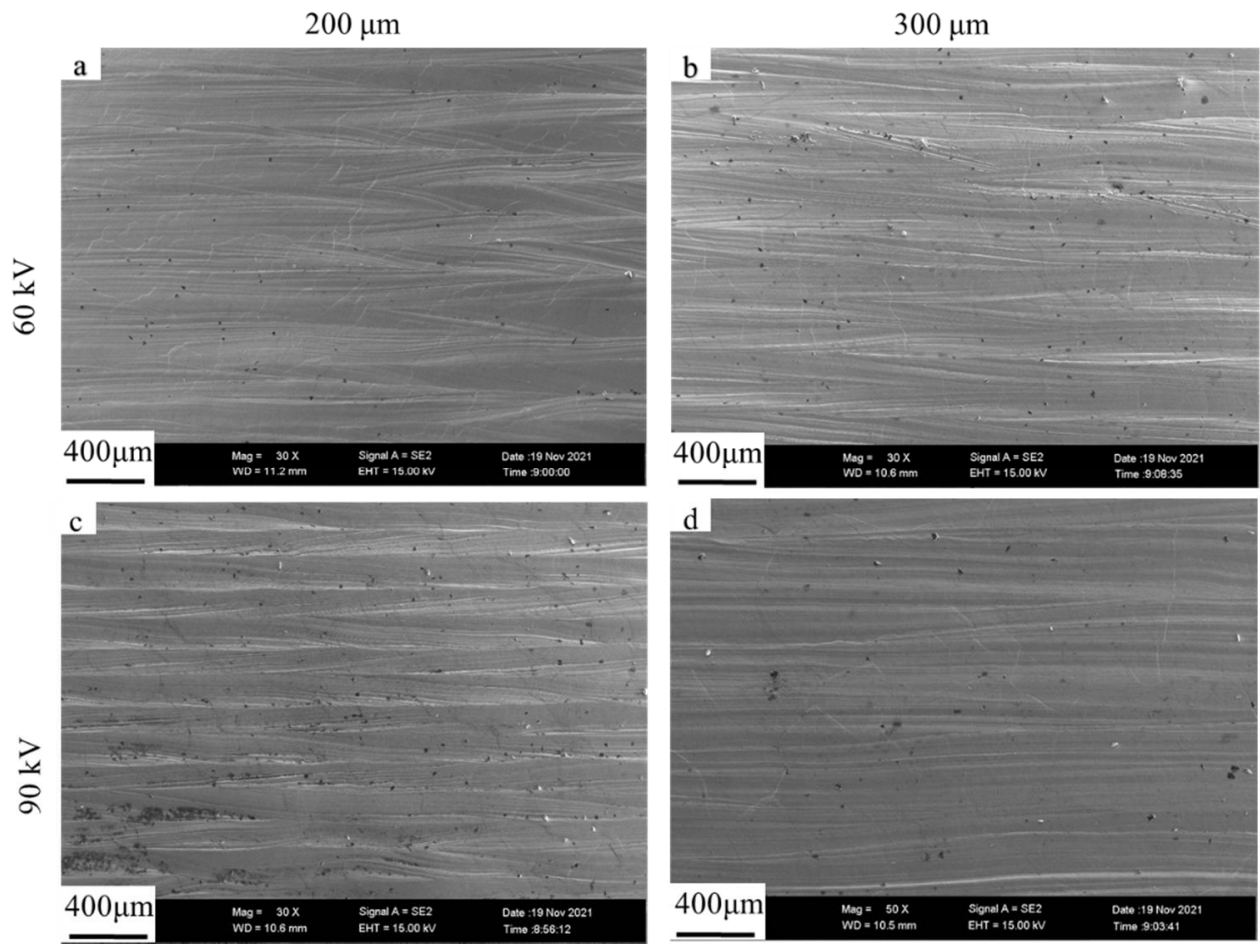

○.

Figure 4. FESEM images of upper surface morphologies for different layer thicknesses and different accelerating voltage values with the bulk energy density of $25 \mathrm{~J} / \mathrm{mm}^{3}$. (a) Sample 3; (b) sample 6; (c) sample 9; (d) sample 12.
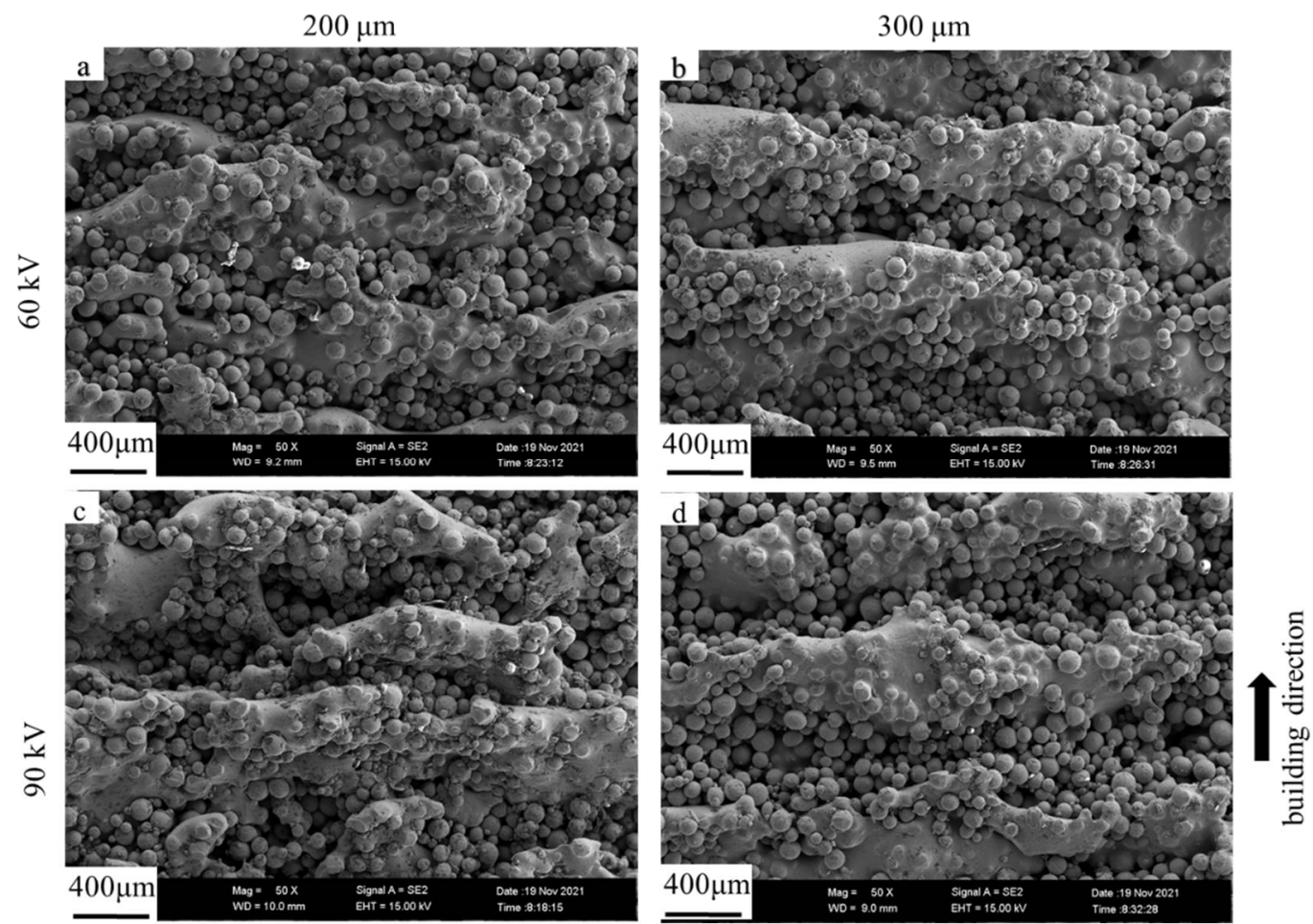

Figure 5. FESEM images of lateral surface morphologies for different layer thicknesses and different accelerating voltage values with the bulk energy density of $25 \mathrm{~J} / \mathrm{mm}^{3}$. (a) Sample 3; (b) sample 6; (c) sample 9; (d) sample 12. 


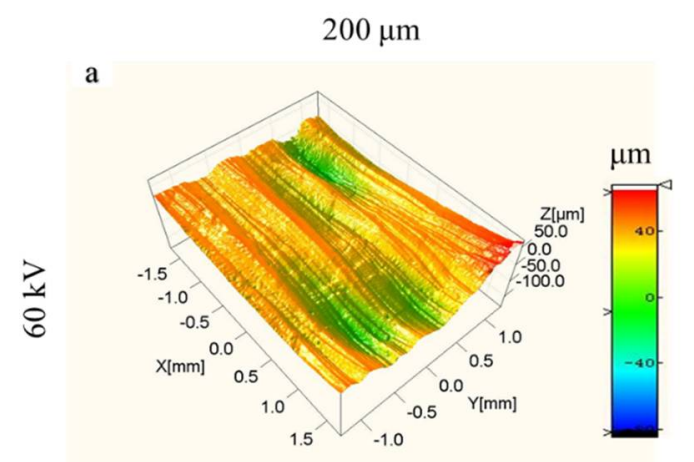

b
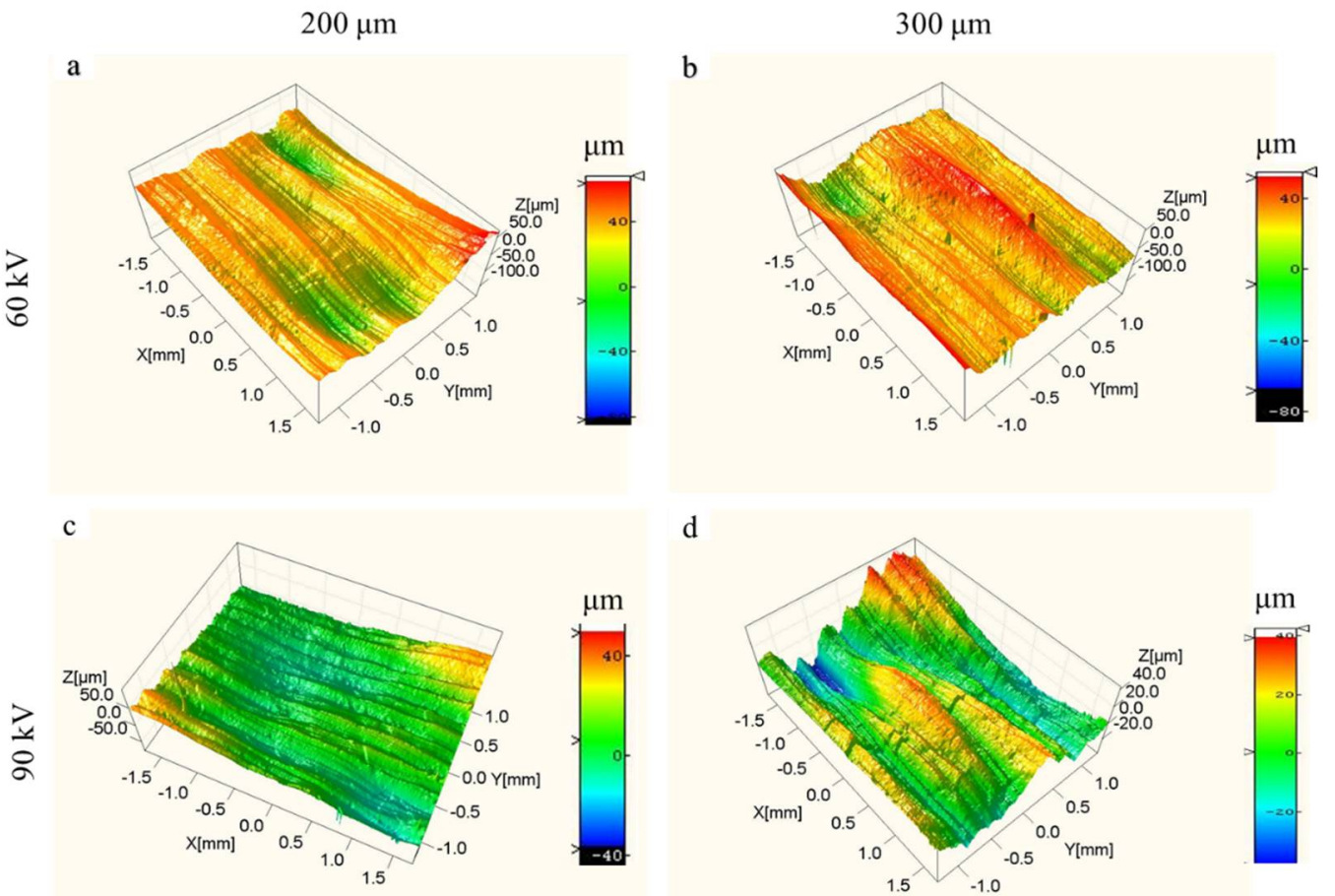

d

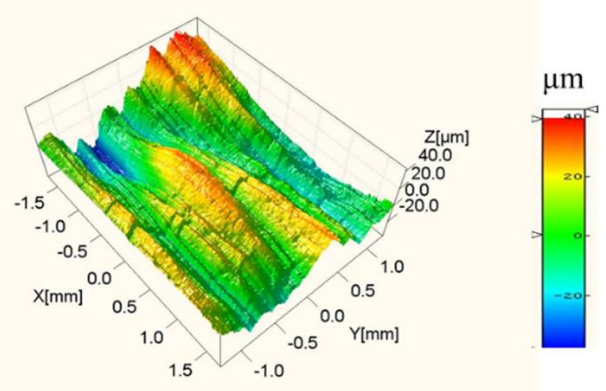

Figure 6. Three-dimensional morphologies of upper surface morphologies for different layer thicknesses and different accelerating voltage values with the bulk energy density of $25 \mathrm{~J} / \mathrm{mm}^{3}$. (a) Sample 3; (b) sample 6; (c) sample 9; (d) sample 12.

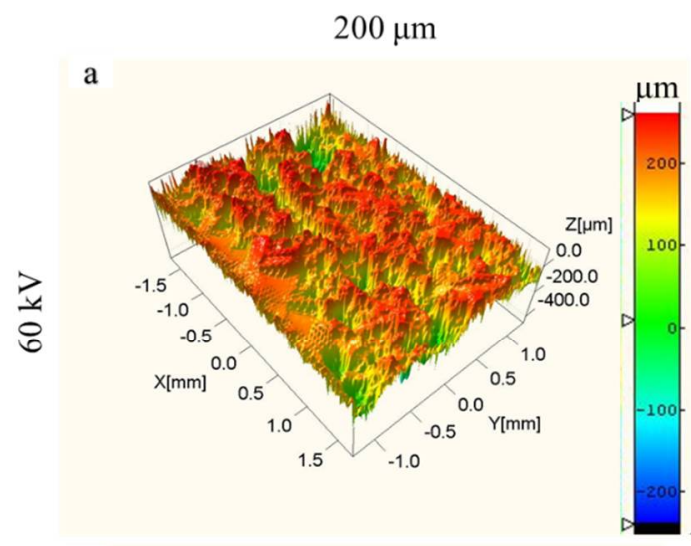

b
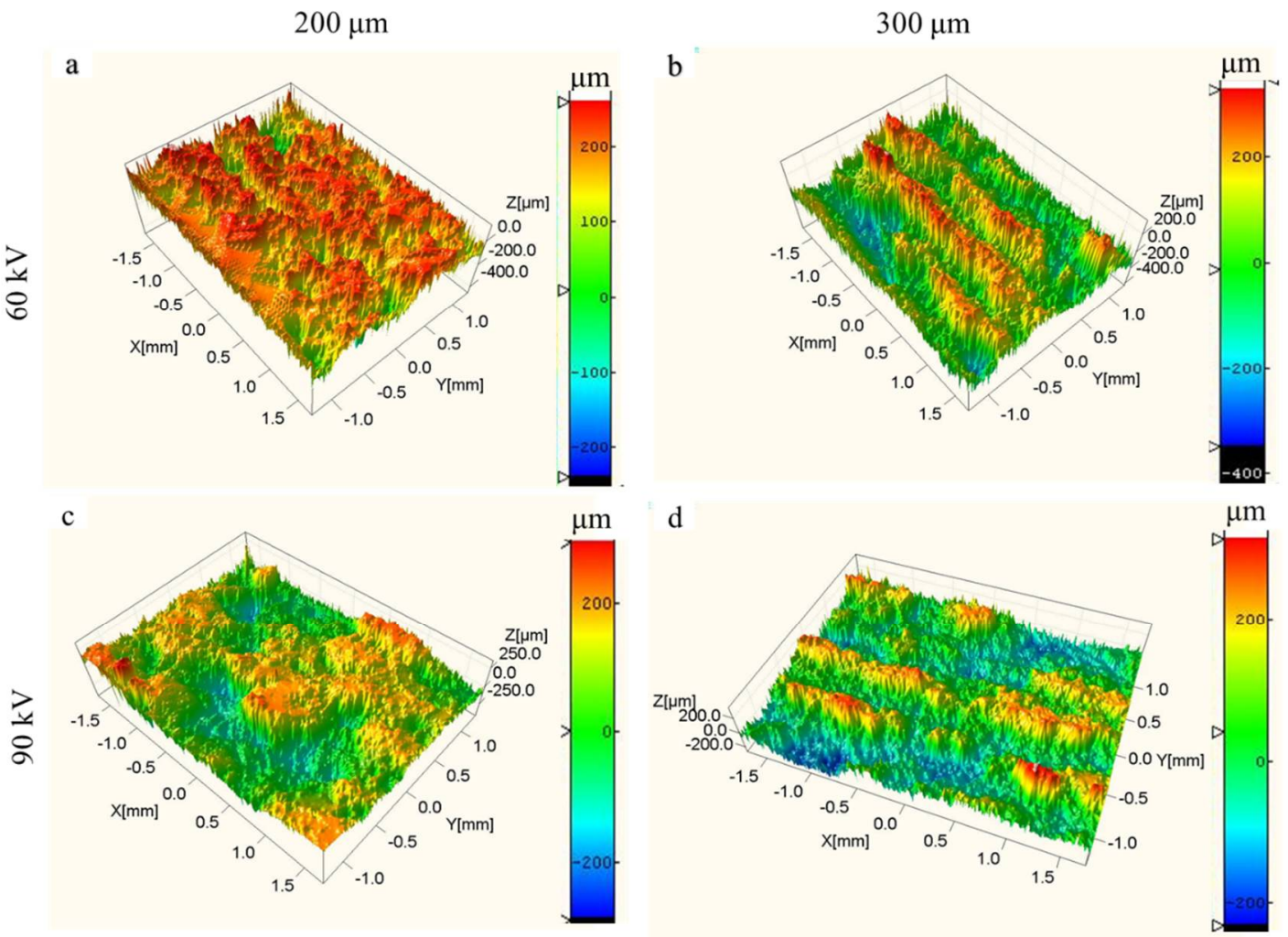

Figure 7. Three-dimensional morphologies of lateral surface morphologies for different layer thicknesses and different accelerating voltage values with the bulk energy density of $25 \mathrm{~J} / \mathrm{mm}^{3}$. (a) Sample 3; (b) sample 6; (c) sample 9; (d) sample 12. 

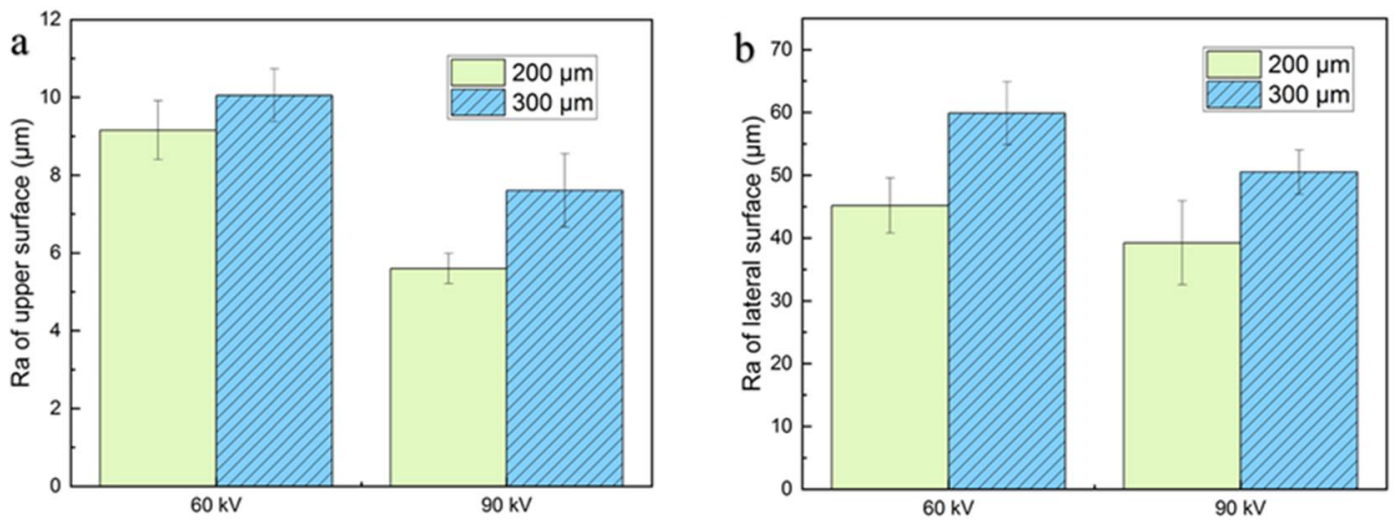

Figure 8. Surface roughness for different layer thicknesses and accelerating voltage values with the bulk energy density of $25 \mathrm{~J} / \mathrm{mm}^{3}$ : (a) upper surface; (b) lateral surface.

The reduction in the minimum bulk energy density required for dense part fabrication due to the escalation of layer thickness can be reflected by the upper surface morphologies. Figure 9 shows the schematic diagram of the melting tracks during the PBF process. The melting depth needed to achieve a dense part was much higher than the nominal layer thickness, which was caused by the stochastic effect that the effect layer thickness varies between zero and several times the nominal layer thickness [28]. Therefore, the section of the melting tracks could be divided into the remelting area and the new melting area and the remelting area should be significantly larger than the new melting area because the molten width and depth are significantly larger than the hatching spacing and layer thickness [22], as shown in Figure 9. When the layer thickness expanded from $200 \mu \mathrm{m}$ to $300 \mu \mathrm{m}$, while the hatching spacing was maintained at $0.2 \mathrm{~mm}$, the new melting area should have been extended by $50 \%$. However, as shown in Figure 8a, the upper surface roughness (Ra) of the dense samples under different layer thicknesses showed a small difference, which indicates that dense parts could be obtained with only a small increase in the height of the overlapping area when the layer thickness expands and the increase in the remelting area should be less than $50 \%$. These facts mean that, when the layer thickness is expanded by $50 \%$, the increase in minimum line energy density $(P / v)$ needed to achieve a dense part should be less than $50 \%$, which results in a decrease in bulk energy density, as shown in Figure 3. In addition, the augmentation of the accelerating voltage enlarges the melting depth and results in a decrease in the bulk energy density to achieve dense parts [22].

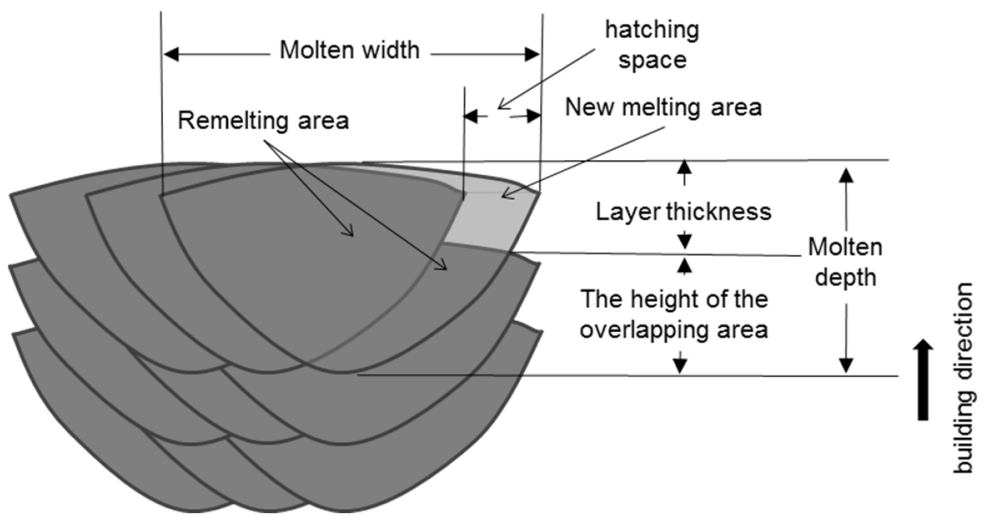

Figure 9. Schematic diagram of the melting tracks during the PBF process.

\subsection{Microstructure}

Figures 10 and 11 demonstrate the microstructures of the as-built samples for the accelerating voltage values of 60 and $90 \mathrm{kV}$ at different layer thicknesses and bulk energy densities, respectively. It can be seen that the microstructure of all the as-built samples 
consisted of the $\alpha$ and $\beta$ phases with a Widmanstätten-like structure; the gray $\alpha$ phase was surrounded by the white $\beta$ phase, which showed no differences in phase compared with the microstructure obtained by low layer thickness [10].
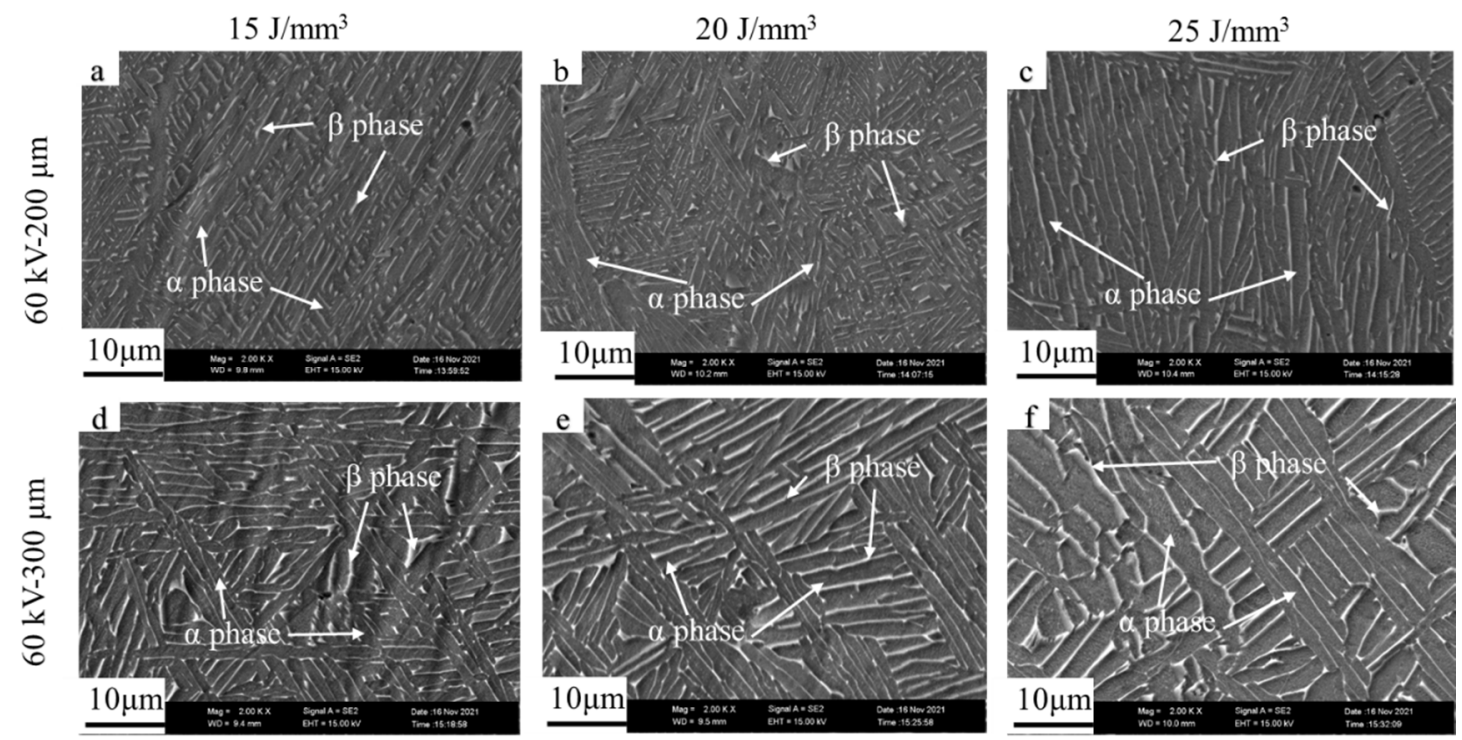

Figure 10. Microstructure of samples for accelerating voltage of $60 \mathrm{kV}$. From (a-f): sample 1 to 6 .
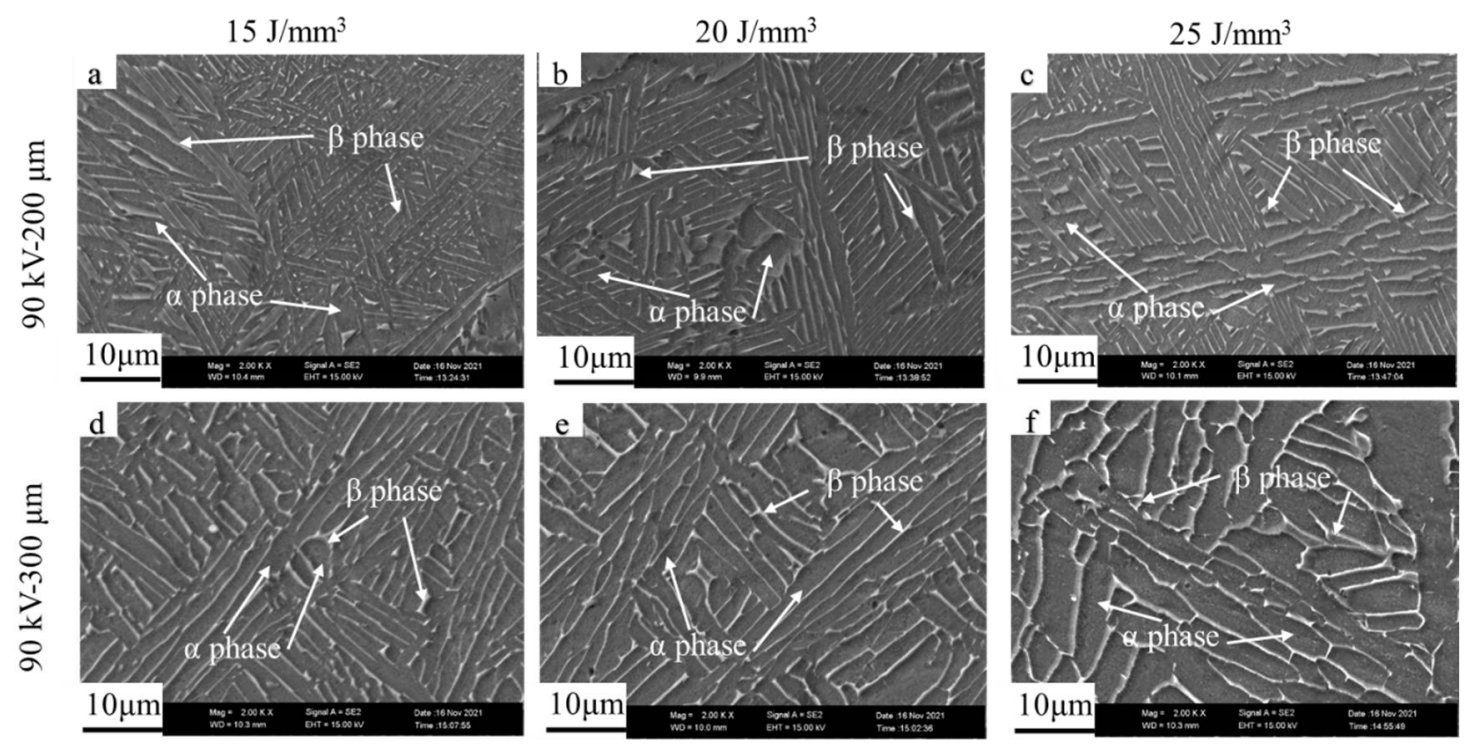

Figure 11. Microstructure of samples for accelerating voltage of $90 \mathrm{kV}$. From (a-f): sample 7 to 12.

The difference in the microstructure of the as-built samples could be characterized by the change in the $\alpha$ platelet thickness, which is plotted in Figure 12. The $\alpha$ platelet thickness is determined by the cooling rate. When the cooling rate decreases, the $\alpha$ platelet has more time to grow up and coarsen [29]. Therefore, with the increase in the bulk energy density or the expansion of the layer thickness under the same bulk energy density, the line energy density (UI/v, defined as the beam power divided by scanning speed) increases and a larger molten pool can be obtained, which results in a lower cooling rate and a thicker $\alpha$ platelet, as shown in Figure 12. In addition, the $\alpha$ platelet thickness also increases with the augmentation of the accelerating voltage, which is caused by the higher energy efficiency and penetrability of the higher accelerating voltage [22]. 


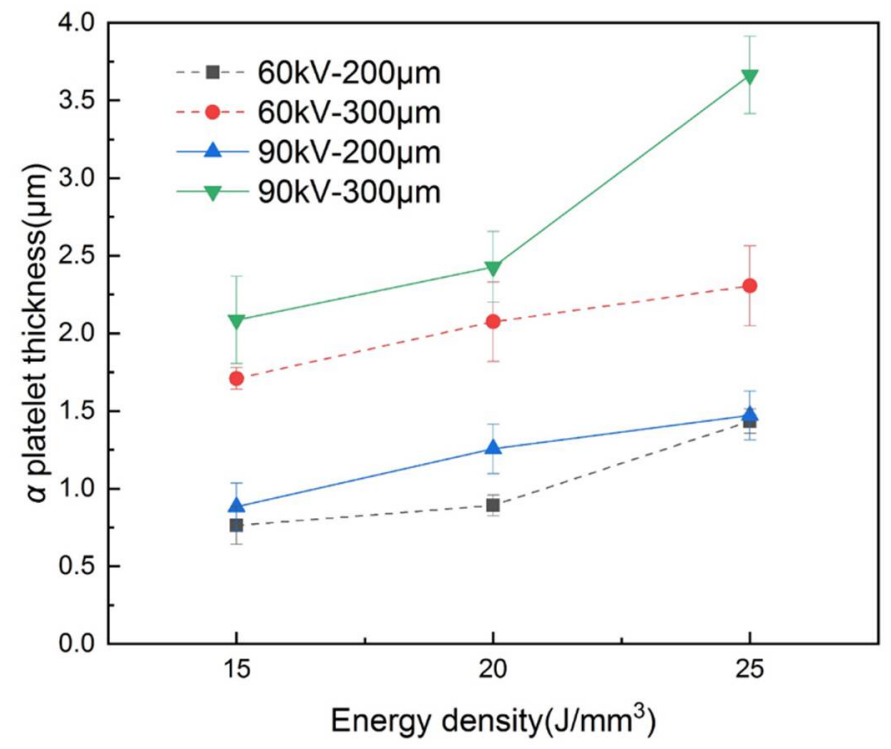

Figure 12. $\alpha$ platelet thickness of as-built samples under different parameters.

\subsection{Tensile Properties}

The mechanical properties of the as-built samples are listed in Table 4 . When the relative density was higher than 99.5\%, an ultimate tensile strength higher than $950 \mathrm{MPa}$ and elongation higher than $9.5 \%$ could be achieved, which agrees with the results obtained by EB-PBF process using layer thickness between 50 and $100 \mu \mathrm{m}[11,22]$. Porosity is the dominant factor in tensile properties [11]. The variation in tensile properties can be explained by unfused defects and entrapped gas in powder particles, as shown in Figures 13 and 14. There were no significant differences between the layer thicknesses of 200 and $300 \mu \mathrm{m}$ when the relative density was higher than $99.5 \%$, which indicates that Ti6Al4V parts with desirable mechanical properties could be obtained with high layer thickness up to $300 \mu \mathrm{m}$ via the EB-PBF process.

Table 4. Mechanical properties for as-built samples.

\begin{tabular}{|c|c|c|c|c|c|c|}
\hline Sample Number & Layer Thickness ( $\mu \mathrm{m})$ & $\begin{array}{l}\text { Accelerating } \\
\text { Voltage (kV) }\end{array}$ & Energy Density $\left(\mathrm{J} / \mathrm{mm}^{3}\right)$ & Yield Strength (MPa) & $\begin{array}{l}\text { Ultimate Tensile } \\
\text { Strength (MPa) }\end{array}$ & Elongation (\%) \\
\hline 1 & 200 & 60 & 15 & $277 \pm 21$ & $283 \pm 17$ & $1.0 \pm 0.1$ \\
\hline 2 & 200 & 60 & 20 & $582 \pm 11$ & $590 \pm 13$ & $0.5 \pm 0.1$ \\
\hline 3 & 200 & 60 & 25 & $969 \pm 7$ & $1077 \pm 3$ & $9.2 \pm 0.4$ \\
\hline 4 & 300 & 60 & 15 & $519 \pm 114$ & $590 \pm 115$ & $1.6 \pm 0.2$ \\
\hline 5 & 300 & 60 & 20 & $962 \pm 2$ & $1072 \pm 5$ & $9.3 \pm 1.9$ \\
\hline 6 & 300 & 60 & 25 & $961 \pm 26$ & $1082 \pm 29$ & $10.3 \pm 0.6$ \\
\hline 7 & 200 & 90 & 15 & $285 \pm 19$ & $310 \pm 37$ & $2.9 \pm 0.2$ \\
\hline 8 & 200 & 90 & 20 & $839 \pm 6$ & $950 \pm 7$ & $13.4 \pm 1.1$ \\
\hline 9 & 200 & 90 & 25 & $840 \pm 20$ & $962 \pm 8$ & $10.4 \pm 0.3$ \\
\hline 10 & 300 & 90 & 15 & $927 \pm 15$ & $1034 \pm 28$ & $9.9 \pm 1.9$ \\
\hline 11 & 300 & 90 & 20 & $877 \pm 13$ & $994 \pm 5$ & $11.3 \pm 0.2$ \\
\hline 12 & 300 & 90 & 25 & $943 \pm 11$ & $1054 \pm 3$ & $10.1 \pm 0.6$ \\
\hline
\end{tabular}

\subsection{Building Rates}

For the PBF process, the building rate is a key parameter that determines the forming efficiency and cost. The building rate can be defined as the volume melted per unit time, which can be calculated by

$$
B=h v L
$$

where $B$ denotes the building rate $\left(\mathrm{mm}^{3} / \mathrm{s}\right)$. 

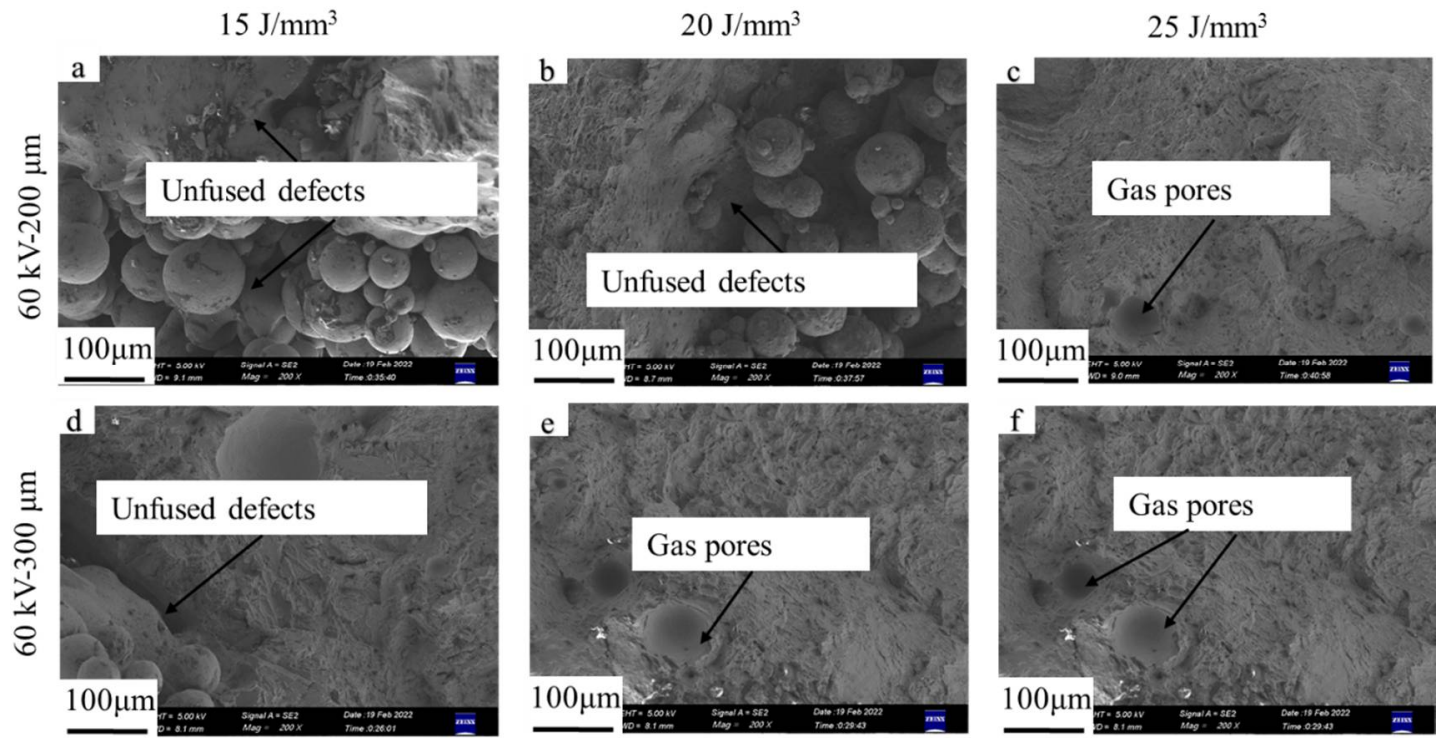

Figure 13. Fracture surfaces of tensile samples for accelerating voltage of $60 \mathrm{kV}$. From (a-f): sample 1 to 6 .
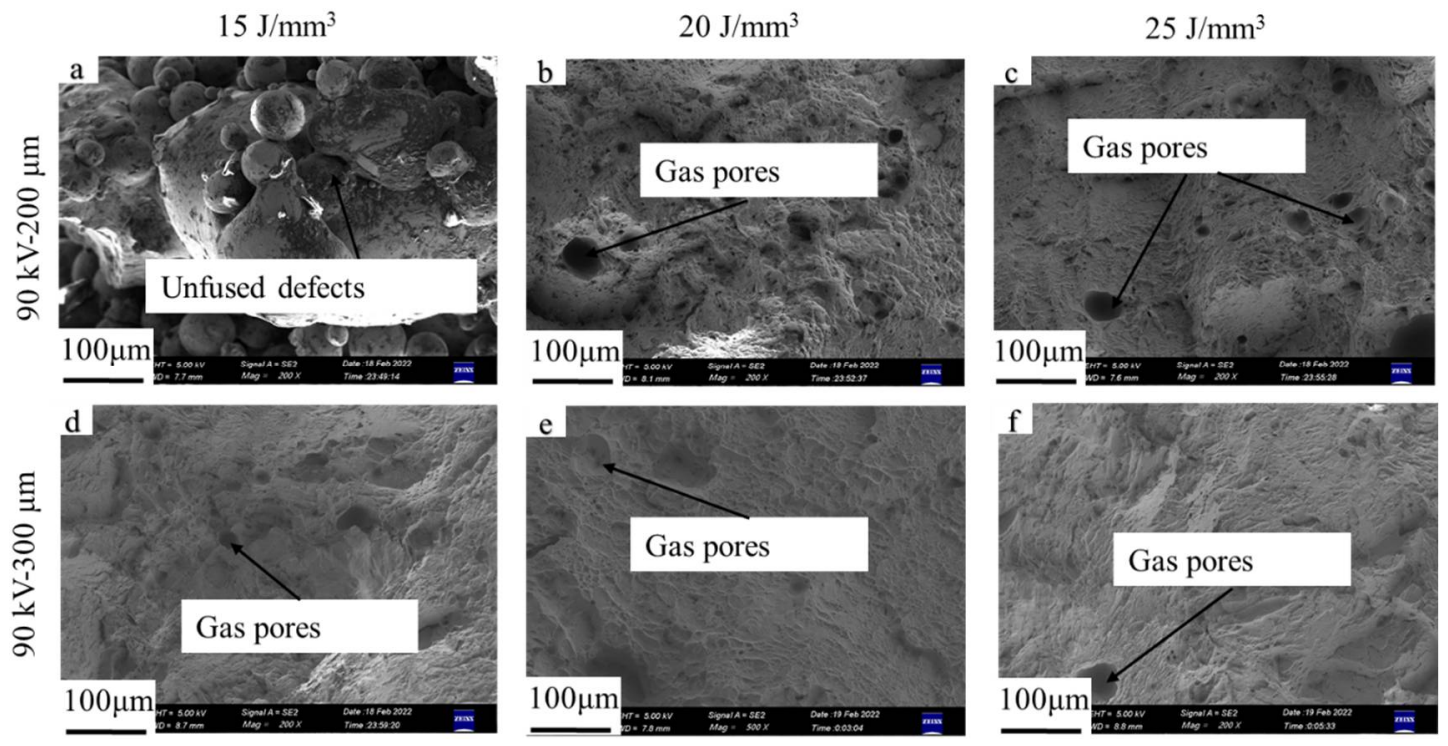

Figure 14. Fracture surfaces of tensile samples for accelerating voltage of $90 \mathrm{kV}$. From (a-f): sample 7 to 12 .

The typical building rates of Ti6Al4V for different PBF processes are listed in Table 5. For the L-PBF process, the building rate is lower than $5 \mathrm{~mm}^{3} / \mathrm{s}$ and can be raised up to $7.2 \mathrm{~mm}^{3} / \mathrm{s}$ by expanding the layer thickness from $30 \mu \mathrm{m}$ to $200 \mu \mathrm{m}$ [14]. As for the EB-PBF process, the typical building rate achieved by the ARCAM machine ranges from 2.5 to $30 \mathrm{~mm}^{3} / \mathrm{s}$ due to different scanning speeds [3]. In this research study, a building rate up to $30 \mathrm{~mm}^{3} / \mathrm{s}$ was achieved using the layer thickness of $300 \mu \mathrm{m}$ and the scanning speed of $500 \mathrm{~mm} / \mathrm{s}$, which is 12 times the typical EB-PBF building rate at the scanning speed of $500 \mathrm{~mm} / \mathrm{s}$ and equivalent to the building rate at the scanning speed of $6000 \mathrm{~mm} / \mathrm{s}$. It should be noted that, when considering the time spent on powder spreading and powder preheating process to build parts of the same height with a high layer thickness, it is significantly lower than that obtained using a low layer thickness; the forming efficiency using layer thickness of $300 \mu \mathrm{m}$ and scanning speed of $500 \mathrm{~mm} / \mathrm{s}$ should be greater than that obtained using layer thickness of $50 \mu \mathrm{m}$ and scanning speed of $6000 \mathrm{~mm} / \mathrm{s}$. 
Table 5. Building rate of different technologies.

\begin{tabular}{cccccc}
\hline Layer Thickness $(\boldsymbol{\mu m})$ & Scanning Speed $(\mathbf{m m} / \mathbf{s})$ & Hatch Space $(\mathbf{m m})$ & Building Rate $\left(\mathbf{m m}^{\mathbf{3}} / \mathbf{s}\right)$ & Manufacturing Technology & Reference \\
\hline 30 & 500 & 0.2 & 3 & 7.2 & L-PBF \\
200 & 60 & 0.6 & 0.1 & $2.5-30$ & L-PBF \\
50 & $500-6000$ & 0.2 & 20 & EB-PBF \\
200 & 500 & 0.2 & $30]$ & EB-PBF & In this research \\
300 & 500 & EB-PBF & In this research \\
\hline
\end{tabular}

\section{Conclusions}

In this research study, layer thicknesses up to $300 \mu \mathrm{m}$ and accelerating voltage values up to $90 \mathrm{kV}$ were used to fabricated Ti6Al4V samples by EB-PBF with different bulk energy densities. The relative densities, surface morphologies, microstructure and mechanical properties of the as-built samples were analyzed and compared using the layer thicknesses of 200 and $300 \mu \mathrm{m}$ and the accelerating voltage values of 60 and $90 \mathrm{kV}$. The conclusions are as follows:

(1) Parts with relative density greater than $99.5 \%$, ultimate tensile strength higher than $950 \mathrm{MPa}$ and elongation higher than $9.5 \%$ were fabricated when the layer thickness expanded to $300 \mu \mathrm{m}$ under both accelerating voltage values. The variation in tensile properties was mainly caused by porosities.

(2) With the increase in the layer thickness or accelerating voltage, the minimum bulk energy density needed to fabricate dense parts decreased due to the decrease in the proportion of the remelted area in the molten pool and the $\alpha$ platelet thickness increased due to the increase in the molten pool.

(3) A higher accelerating voltage enlarged the melting depth, which improved the surface finish even if it was impaired due to the expansion of layer thickness.

(4) A building rate up to $30 \mathrm{~mm}^{3} / \mathrm{s}$ without sacrificing the mechanical properties could be achieved when the layer thickness was $300 \mu \mathrm{m}$, the hatch space was $200 \mu \mathrm{m}$ and the scanning speed was $500 \mathrm{~mm} / \mathrm{s}$.

Author Contributions: Conceptualization, H.L.; methodology, H.L. and Y.L.; validation, F.L., X.L. and Y.L.; formal analysis, H.L.; investigation, H.L. and Y.L.; data curation, H.L.; writing-original draft preparation, H.L.; writing—review and editing, X.L. and F.L.; visualization, H.L.; supervision, F.L.; funding acquisition, F.L. All authors have read and agreed to the published version of the manuscript.

Funding: This research was funded by [the National Key R\&D Program of China] grant number [2018YFB1105204].

Conflicts of Interest: The authors declare no conflict of interest.

\section{References}

1. Körner, C. Additive manufacturing of metallic components by selective electron beam melting-A review. Int. Mater. Rev. 2016, 61,361-377. [CrossRef]

2. Guo, C.; Ge, W.; Lin, F. Effects of scanning parameters on material deposition during Electron Beam Selective Melting of Ti-6Al-4V powder. J. Mater. Process. Technol. 2015, 217, 148-157. [CrossRef]

3. Juechter, V.; Scharowsky, T.; Singer, R.F.; Körner, C. Processing window and evaporation phenomena for Ti-6Al-4V produced by selective electron beam melting. Acta Mater. 2014, 76, 252-258. [CrossRef]

4. Li, Y.; Liang, X.; Yu, Y.; Li, H.; Kan, W.; Lin, F. Microstructures and mechanical properties evolution of IN939 alloy during electron beam selective melting process. J. Alloys Compd. 2021, 883, 160934. [CrossRef]

5. Kenevisi, M.S.; Lin, F. Selective electron beam melting of high strength A12024 alloy; microstructural characterization and mechanical properties. J. Alloys Compd. 2020, 843, 155866. [CrossRef]

6. Zhong, Y.; Rännar, L.-E.; Liu, L.; Koptyug, A.; Wikman, S.; Olsen, J.; Cui, D.; Shen, Z. Additive manufacturing of 316L stainless steel by electron beam melting for nuclear fusion applications. J. Nucl. Mater. 2017, 486, 234-245. [CrossRef]

7. Ramirez, D.A.; Murr, L.E.; Li, S.J.; Tian, Y.X.; Martinez, E.; Martinez, J.L.; Machado, B.I.; Gaytan, S.M.; Medina, F.; Wicker, R.B. Open-cellular copper structures fabricated by additive manufacturing using electron beam melting. Mater. Sci. Eng. A 2011, 528, 5379-5386. [CrossRef]

8. Ramsperger, M.; Singer, R.F.; Körner, C. Microstructure of the Nickel-Base Superalloy CMSX-4 Fabricated by Selective Electron Beam Melting. Metallurg. Mater. Trans. A 2016, 47, 1469-1480. [CrossRef] 
9. Zhou, J.; Li, H.; Yu, Y.; Li, Y.; Qian, Y.; Firouzian, K.; Lin, F. Research on aluminum component change and phase transformation of TiAl-based alloy in electron beam selective melting process under multiple scan. Intermetallics 2019, 113, 106575. [CrossRef]

10. Karlsson, J.; Snis, A.; Engqvist, H.; Lausmaa, J. Characterization and comparison of materials produced by Electron Beam Melting (EBM) of two different Ti-6Al-4V powder fractions. J. Mater. Process. Technol. 2013, 213, 2109-2118. [CrossRef]

11. Galarraga, H.; Lados, D.A.; Dehoff, R.R.; Kirka, M.M.; Nandwana, P. Effects of the microstructure and porosity on properties of Ti-6Al-4V ELI alloy fabricated by electron beam melting (EBM). Addit. Manuf. 2016, 10, 47-57. [CrossRef]

12. DebRoy, T.; Mukherjee, T.; Milewski, J.O.; Elmer, J.W.; Ribic, B.; Blecher, J.J.; Zhang, W. Scientific, technological and economic issues in metal printing and their solutions. Nat. Mater. 2019, 18, 1026-1032. [CrossRef] [PubMed]

13. Ma, M.; Wang, Z.; Gao, M.; Zeng, X. Layer thickness dependence of performance in high-power selective laser melting of 1Cr18Ni9Ti stainless steel. J. Mater. Process. Technol. 2015, 215, 142-150. [CrossRef]

14. Shi, X.; Ma, S.; Liu, C.; Chen, C.; Wu, Q.; Chen, X.; Lu, J. Performance of High Layer Thickness in Selective Laser Melting of Ti6Al4V. Materials 2016, 9, 975. [CrossRef]

15. Sufiiarov, V.S.; Popovich, A.A.; Borisov, E.V.; Polozov, I.A.; Masaylo, D.V.; Orlov, A.V. The Effect of Layer Thickness at Selective Laser Melting. Proced. Eng. 2017, 174, 126-134. [CrossRef]

16. Wang, S.; Liu, Y.; Shi, W.; Qi, B.; Yang, J.; Zhang, F.; Han, D.; Ma, Y. Research on High Layer Thickness Fabricated of 316L by Selective Laser Melting. Materials 2017, 10, 1055. [CrossRef]

17. Shi, W.; Wang, P.; Liu, Y.; Hou, Y.; Han, G. Properties of 316L formed by a $400 \mathrm{~W}$ power laser Selective Laser Melting with $250 \mu \mathrm{m}$ layer thickness. Powder Technol. 2020, 360, 151-164. [CrossRef]

18. Shi, X.; Yan, C.; Feng, W.; Zhang, Y.; Leng, Z. Effect of high layer thickness on surface quality and defect behavior of Ti-6Al-4V fabricated by selective laser melting. Opt. Laser Technol. 2020, 132, 106471. [CrossRef]

19. Shi, W.; Liu, Y.; Shi, X.; Hou, Y.; Wang, P.; Song, G. Beam Diameter Dependence of Performance in Thick-Layer and High-Power Selective Laser Melting of Ti-6Al-4V. Materials 2018, 11, 1237. [CrossRef] [PubMed]

20. Tang, H.P.; Yang, G.Y.; Jia, W.P.; He, W.W.; Lu, S.L.; Qian, M. Additive manufacturing of a high niobium-containing titanium aluminide alloy by selective electron beam melting. Mater. Sci. Eng. A 2015, 636, 103-107. [CrossRef]

21. Rännar, L.-E.; Koptyug, A.; Olsén, J.; Saeidi, K.; Shen, Z. Hierarchical structures of stainless steel 316L manufactured by Electron Beam Melting. Addit. Manuf. 2017, 17, 106-112. [CrossRef]

22. Li, H.; Yu, Y.; Li, Y.; Lin, F. Effects of the higher accelerating voltage on electron beam powder-bed based additive manufacturing of Ti6Al4V alloy. Addit. Manuf. 2022, 50, 102579. [CrossRef]

23. Dumonte, P.; Sayegh, G. Effects of Accelerating Voltage on the Penetration in Electron-Beam Welding. In Advances in Welding Processses, Proceedings of the Third International Conference, Harrogate, UK, 7-9 May 1974; Needham, J.C., Ed.; Welding Institute: Cambridge, UK, 1974; Volume 1-2, pp. 160-167.

24. Guo, C.; Ge, W.; Lin, F. Dual-Material Electron Beam Selective Melting: Hardware Development and Validation Studies Engineering 2015, 1, 124-130. [CrossRef]

25. Guo, C.; Zhang, J.; Zhang, J.; Ge, W.; Yao, B.; Lin, F. Scanning system development and digital beam control method for electron beam selective melting. Rapid Prototyp. J. 2015, 21, 313-321. [CrossRef]

26. Puebla, K.; Murr, L.E.; Gaytan, S.M.; Martinez, E.; Medina, F.; Wicker, R.B. Effect of Melt Scan Rate on Microstructure and Macrostructure for Electron Beam Melting of Ti-6Al-4V. Mater. Sci. Appl. 2012, 03, 259-264. [CrossRef]

27. Wu, C.; Zafar, M.Q.; Zhao, H.; Wang, Y.; Schöler, C.; Heinigk, C.; Nießen, M.; Schulz, W. Multi-physics modeling of side roughness generation mechanisms in powder bed fusion. Addit. Manuf. 2021, 47, 102274. [CrossRef]

28. Bauereiß, A.; Scharowsky, T.; Körner, C. Defect generation and propagation mechanism during additive manufacturing by selective beam melting. J. Mater. Process. Technol. 2014, 214, 2522-2528. [CrossRef]

29. Scharowsky, T.; Juechter, V.; Singer, R.F.; Korner, C. Influence of the Scanning Strategy on the Microstructure and Mechanical Properties in Selective Electron Beam Melting of Ti-6Al-4V. Adv. Eng. Mater. 2015, 17, 1573-1578. [CrossRef]

30. Vilaro, T.; Colin, C.; Bartout, J.D. As-Fabricated and Heat-Treated Microstructures of the Ti-6Al-4V Alloy Processed by Selective Laser Melting. Metall. Mater. Trans. A 2011, 42, 3190-3199. [CrossRef] 